\title{
Local administration of glucocorticoids decreases synovial citrullination in rheumatoid arthritis
}

\author{
Dimitrios Makrygiannakis ${ }^{1}$, Shankar Revu', Marianne Engström¹, Erik af Klint ${ }^{1}$, Anthony P Nicholas ${ }^{2}$, Ger JM Pruijn $^{3}$ \\ and Anca I Catrina ${ }^{1 *}$
}

\begin{abstract}
Introduction: Protein citrullination is present in the rheumatoid synovium, presumably contributing to the perpetuation of chronic inflammation, in the presence of specific autoimmunity. As a result, the present study examined the possibility that effective antirheumatic treatment will decrease the level of synovial citrullination.

Methods: Synovial biopsies were obtained from 11 rheumatoid arthritis (RA) patients before and after 8 weeks of treatment with $20 \mathrm{mg}$ methotrexate weekly, 15 RA patients before and 2 weeks after an intraarticular glucocorticoid injection, and eight healthy volunteers. Synovial inflammation was assessed with double-blind semiquantitative analysis of lining thickness, cell infiltration, and vascularity by using a 4-point scale. Expression of citrullinated proteins (CPS) with the monoclonal antibody F95 and peptidylarginine deiminase (PAD) 2 and 4 was assessed immunohistochemically with double-blind semiquantitative analysis. In vitro synovial fluid (SF), peripheral blood (PB), mononuclear cells (MCs), and synovial explants obtained from RA patients were incubated with dexamethasone and analyzed with immunohistochemistry for expression of CP as well as PAD2 and PAD4 enzymes.
\end{abstract}

Results: The presence of synovial CP was almost exclusive in RA compared with healthy synovium and correlated with the degree of local inflammation. Treatment with glucocorticoids but not methotrexate alters expression of synovial CP and PAD enzymes, in parallel with a decrease of synovial inflammation. Ex vivo and in vitro studies suggest also a direct effect of glucocorticoids on citrullination, as demonstrated by the decrease in the level of citrullination and PAD expression after incubation of SFMC and synovial explants with dexamethasone.

Conclusion: Synovial citrullination and PAD expression are dependent on local inflammation and targeted by glucocorticoids.

\section{Introduction}

Rheumatoid arthritis (RA) is a chronic inflammatory disease characterized by the presence of highly specific anti-citrullinated protein antibodies (ACPAs) [1]. These antibodies recognize several different proteins that are citrullinated. Citrullination is the conversion of peptidylarginine to peptidylcitrulline through a calcium-dependent process catalyzed by the peptidylarginine deiminase (PAD) enzymes. Five PAD isotypes have been described in humans (PAD1, PAD2, PAD3, PAD4, and PAD6), which are expressed in a variety of tissues, but only PAD2 and PAD4 have been found to be expressed in

\footnotetext{
* Correspondence: Anca.Catrina@ki.se

'Department of Medicine, Rheumatology Unit, Karolinska University Hospital, Karolinska Institutet, SE- 141 86, Stockholm, Sweden

Full list of author information is available at the end of the article
}

inflamed synovial tissue of RA and other inflammatory arthritides [2].

Despite the high specificity of ACPA in RA in comparison to other arthritides and other inflammatory diseases [3], the presence of CP is not restricted to RA synovial tissue $[4,5]$, but rather associated with inflammation in general [6]. Synovial citrullination appears therefore not to be essential for the predisease phase of induction of specific anti-citrulline immunity. Conversely, protein citrullination enhances the HLA binding capacity of synovial-derived proteins and promotes NF$\kappa \mathrm{B}$ and tumor necrosis factor (TNF) production in the presence ACPA [7]. This suggests that local synovial citrullination might be essential in a later phase of the disease process, contributing to occurrence and perpetuation of chronic synovitis in the presence of specific

\section{Biomed Central}


anti-citrulline antibodies. It is therefore conceivable that downregulation of synovial citrullination by any means will contribute to the resolution of local inflammation. We hypothesize that effective antirheumatic treatment with either antiinflammatory, intraarticular glucocorticoids (GCs), or a disease-modifying antirheumatic drug, such as methotrexate (MTX) will decrease synovial citrullination in vivo. As a result, the present study aimed to investigate any direct effect of these drugs on protein citrullination.

\section{Materials and methods Patients}

Twenty-six patients meeting the 1987 American College of Rheumatology criteria for RA [8] were recruited for this study. In a first group, 11 patients (six women and five men; median age, 56 years; range, 33 to 78 years) with newly diagnosed RA (symptom duration less than 1 year) previously disease-modifying antirheumatic drug (DMARD) naïve were started on MTX, $10 \mathrm{mg}$ weekly, and reached a stable dose of $20 \mathrm{mg}$ after 2 weeks, increasing the dose with $5 \mathrm{mg}$ every week. Synovial biopsy samples were obtained by arthroscopy from all patients before and after a median of 8 weeks of treatment. Clinical evaluation of the therapeutic response according to EULAR response criteria was performed a median of 3 months after methotrexate initiation. In a second group, 15 RA patients (11 women and four men; median age, 63 years; range, 34 to 83 years) with active knee arthritis independent of disease duration received an intraarticular injection of $40 \mathrm{mg}$ of triamcinolone hexacetonide, and synovial biopsy samples were obtained with arthroscopy before and after 2 weeks after intraarticular treatment. In this second group, associated DMARD treatments were stable for at least 2 weeks before initiation of treatment and throughout the entire study period. Clinical evaluation of the therapeutic response was performed with macroscopic scoring of the level of inflammation during arthroscopy. Nonsteroidal antiinflammatory drugs and per-oral prednisolone to a maximum dose of $10 \mathrm{mg}$ daily were permitted in both groups. Additionally, synovial biopsy samples were obtained with arthroscopy in eight healthy volunteers. All procedures were approved by the Northern Stockholm Ethical Review Board, and informed consent was obtained from all the participants in the study.

\section{Synovial biopsies handling}

Synovial biopsy samples were snap-frozen during arthroscopy in dry-ice cooled isopentane. Serial cryostat sections $(7 \mu \mathrm{m})$ were fixed for 20 minutes with $2 \%$ (vol/vol) formaldehyde and stored at $-70^{\circ} \mathrm{C}$.

\section{Cell culturing}

Paired peripheral blood mononuclear cells (PBMCs) and synovial fluid mononuclear cells (SFMCs) from RA patients $(n=6)$ were cultured as duplicates in RPMI 1640 supplemented with $20 \%$ heat-inactivated fetal bovine serum (FBS), $2 \mathrm{mM}$ L-glutamine, $50 \mathrm{IU} / \mathrm{ml}$ penicillin, and $50 \mu \mathrm{g} / \mathrm{ml}$ streptomycin (Gibco, Carlsbad, CA, USA) and incubated at $37^{\circ} \mathrm{C}$ with $5 \% \mathrm{CO}_{2}$ in a humidified atmosphere. Cells were grown at a density of $1 \times 10^{6}$ per $\mathrm{ml}$ in polypropylene tubes and incubated with dexamethasone for 24 hours at a final concentration of 1 and $100 \mu \mathrm{M}$ DXM. After treatment, cells were washed, resuspended in PBS, and seeded on glass slides (Thermo Scientific diagnostic microscopic glass slides, Braunschweig, Germany). Adherent cells were fixed for 20 minutes at $4^{\circ} \mathrm{C}$ with $2 \%$ (vol/vol) formaldehyde (Merck, Darmstadt, Germany).

\section{Synovial explants}

Synovial tissue pieces obtained from an orthopedic hipreplacement surgery in an RA patient were selected based on maximal macroscopic score of inflammation, dissected and seeded on 24-well plates in RPMI, supplemented with $10 \%$ heat-inactivated fetal calf serum (FCS), $2 \mathrm{~m} M$ L-glutamine, $50 \mathrm{IU} / \mathrm{ml}$ penicillin, and 50 $\mu \mathrm{g} / \mathrm{ml}$ streptomycin (Gibco), and incubated at $37^{\circ} \mathrm{C}$ with $5 \% \mathrm{CO}_{2}$ in a humidified atmosphere for 24 hours with $100 \mu M$ DXM. Tissue pieces were then transferred to six-well plates and cultured for additional 5 days with fresh prepared serum supplemented with the same concentrations of the drugs. At the end of the incubation, medium was removed, and tissue pieces were cryosectioned, fixed for 20 minutes at $4{ }^{\circ} \mathrm{C}$ with $2 \%$ (vol/vol) formaldehyde (Merck), and stored at $-80^{\circ} \mathrm{C}$.

\section{Immunohistochemistry and histologic evaluation}

Presence of citrullinated proteins (CPs) was detected by using a mouse IgM monoclonal antibody (F95), which was raised against a decacitrullinated peptide linked to the carrier protein, keyhole limpet hemocyanin [9-11]. For detection of PAD enzyme expression, we used two PAD4 (SN823 and SG1467) [12,13] and one PAD2 (SN665) [12] rabbit polyclonal antibodies and one additional rabbit polyclonal antibody (ROI002) (CosmoBio, Tokyo, Japan) to identify PAD2 expression [14]. Appropriate negative controls were used for each antibody.

Two independent observers (DM and AIC), who were unaware of the sample's identity, scored the presence of $\mathrm{CP}$ and PAD enzymes in synovial tissue by using a 4point scale ( 0 , no staining; 1 , low amounts of staining; 2 , moderate amounts of staining; 3 , high amounts of staining). In parallel, histologic scoring of the degree of inflammation was performed, by using a 4-point scale, by double-blind semiquantitative analysis (DM and SR) of the lining thickness, infiltration level, and vascularity 
in serial hematoxylin eosin staining. In every instance, the final scores represent the mean of the two observations. The presence of CP and PAD enzymes in SFMCs and PBMCs was assessed with manual counting of positive cells and expressed as a percentage of positive cells in the total number of the cells.

\section{Statistical analysis}

Statistical analysis was performed by using the Wilcoxon test for comparison of paired samples, the Mann-Whitney test for comparison of independent samples, and the Spearmen rank correlation test. All comparisons were planned, and therefore, no Bonferroni correction was applied. Differences between proportions were analyzed with the Fisher Exact test. In vitro experiments results were analyzed by using one-way (ANOVA) analysis of variance, as appropriate. $P$ values less than 0.05 were considered statistically significant.

\section{Results}

Intracellular but not extracellular presence of citrullinated peptides is RA specific

It was previously suggested that the intracellular pattern of F95 staining is a specific trait of RA as compared with healthy synovium [11]. Further to investigate this, we analyzed the immunohistochemical expression of citrullinated peptides (as detected by F95 antibody) and the PAD2 and PAD4 enzymes in baseline RA samples obtained before initiation of treatment, as compared with healthy synovial biopsies. Intracellular F95 staining was readily detected in RA samples (24 of $28,85.7 \%$ ) and absent in healthy synovium (none of eight; $P<$ 0.05 ). Extracellular F95 staining was present in RA (24 of $28,85.7 \%$ ) and to a lesser extent in healthy synovial tissue (one of eight, $12.5 \% ; P<0.05$ ). PAD2 and PAD4 expression was detected in all baseline RA samples (100\%) and a vast majority of the healthy synovial biopsies (seven of eight, 87.5\% positive for ROI002 antibody; six of eight, 75\% positive for SN665 antibody; all eight, $100 \%$ positive for SG1467 antibody, and seven of eight, $87.5 \%$ positive for SN8233 antibody) and with a general higher expression of all investigated molecules in RA as compared with healthy synovium (Figure $1 ; P<0.05$ for all investigated antibodies).

\section{Synovial citrullination and PAD expression correlate with the degree of inflammation}

To investigate further the relation between inflammation and citrullination, we analyzed the correlation between the presence of total and intracellular CP, as well as PAD enzymes, and the degree of local inflammation in baseline samples obtained from all RA patients and healthy individuals $(n=34)$. As expected, most of the investigated markers correlated with the degree of lining thickness, cell infiltration, and vascularity (Table 1).

Intraarticular GC, but not MTX, decreases synovial citrullination and PAD4 expression

The observed correlation between inflammation and citrullination prompted us to investigate the effect of antirheumatic treatment on synovial citrullination and PAD expression.

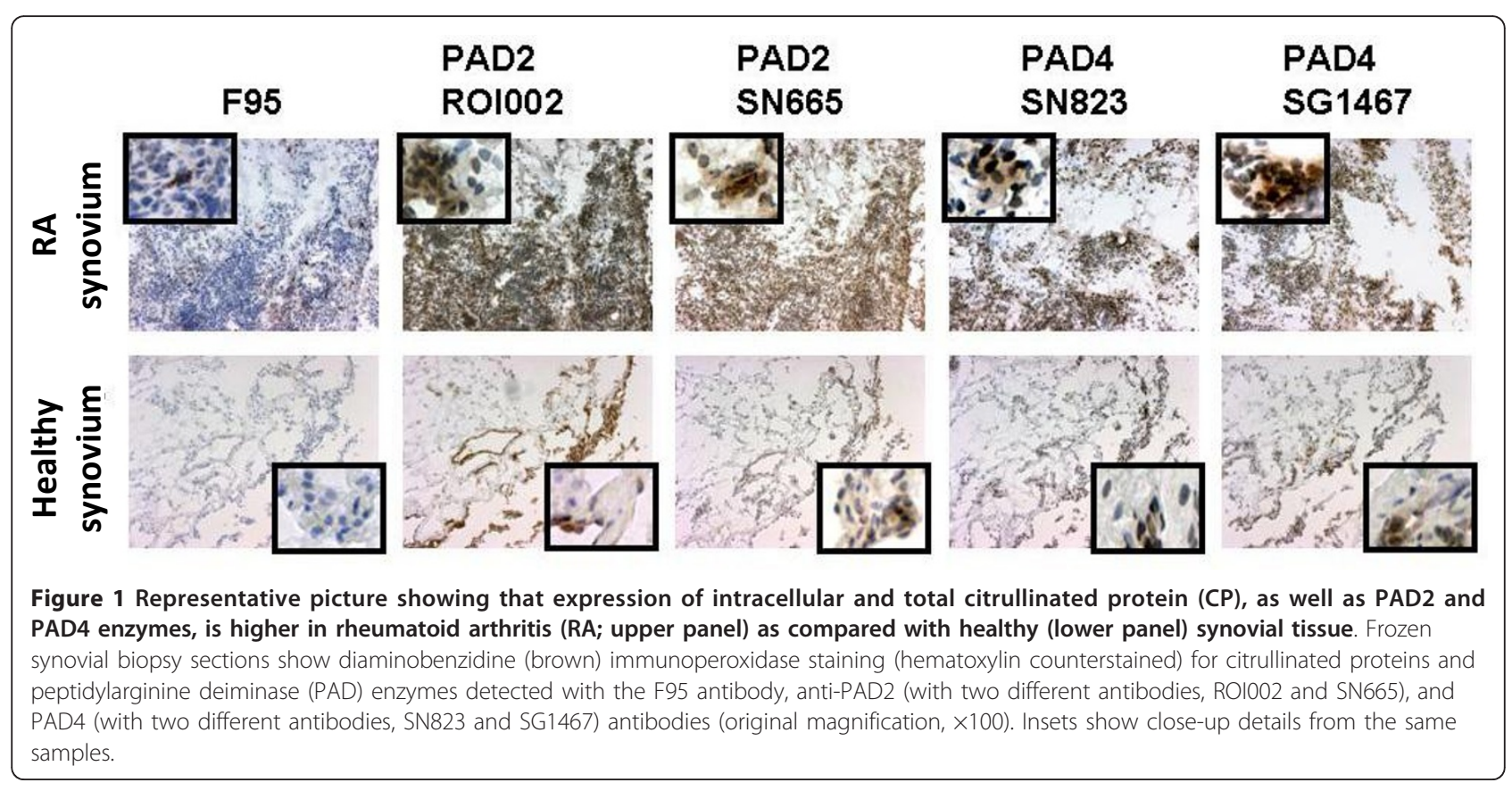


Table 1 Correlations between CP, PAD2, and PAD4 expression and synovial inflammation

\begin{tabular}{llll}
\hline & Mean lining thickness & Infiltration & Vascularity \\
\hline Total CP & $0.4(<0.05)$ & $0.5(<0.001)$ & $0.6(<0.001)$ \\
Intracellular CP & $0.4(<0.05)$ & $0.4(0.001)$ & $0.6(<0.01)$ \\
PAD2 (ROI002) & $0.5(<0.05)$ & $0.6(<0.001)$ & $0.4(<0.05)$ \\
PAD2 (SN665) & $0.6(<0.001)$ & $0.7(<0.001)$ & $0.5(<0.01)$ \\
PAD4 (SG1467) & $0.6(<0.01)$ & $0.3(\mathrm{NS})$ & $0.3(\mathrm{NS})$ \\
PAD4 (SN823) & $0.5(<0.01)$ & $0.1(\mathrm{NS})$ & $0.2(\mathrm{NS})$ \\
\hline
\end{tabular}

Values are expressed as Spearman rank correlation coefficients ( $P$ values). $\mathrm{CP}$, citrullinated protein; NS, not significant.

Local administration of GC significantly decreased both total and intracellular expression of CP from a median score of 2 (range, 0 to 3 ) to a median score of 1 (range, 0 to 2 ), $P<0.05$. PAD4 expression also decreased after treatment from a median score of 2 (range, 1 to 3 ) to a median score of 1 (range, 0 to 2.5), $P<0.05$, when evaluated with the SG1467 antibody and to a lesser extent when evaluated with the SN823 antibody $(P=0.06)$, whereas no changes were observed for PAD2 expression after intraarticular administration of GCs (Figure 2). The GC effect on citrullination and PAD expression was paralleled by a significant decrease $(P<0.05)$ in the lining thickness (from a median score of 1 , range, 0 to 2 , to a median score of 0.5 , range, 0 to 1 ) and cell infiltration (from a median score of 3 , range, 2 to 3 , to a median score of 2 , range, 1 to 3 ), but not vascularity. All patients were good clinical responders, as evaluated with macroscopic investigation of the joint inflammation at the time of arthroscopy and retrospective scoring of photo records.

In contrast, methotrexate treatment had no effect on either synovial inflammation or local expression of $\mathrm{CP}$ and PAD (Figure 3), despite a good clinical response in nine of 11 treated patients with a significant decrease in the DAS28 score from a mean \pm SEM of $5.5 \pm 0.3$ to a mean \pm SEM of $3.4 \pm 0.4$ after 3 months of treatment. Interestingly, the same was true when only EULAR responders $(n=9)$ were included in the analysis.

In vitro GCs have a direct effect on cellular expression of $\mathrm{CP}$, potentially through a PAD-dependent mechanism

Apart from their inflammation-damping effect, GCs may also directly target the process of citrullination. To investigate this, we tested the effect of DXM on CP and PAD enzymes expression in vitro in SFMC and PBMC paired samples of RA individuals. Confirming our in vivo results, DXM decreased the expression of CP, PAD4, but also PAD2, in SFMC (Figure 4) but not PBMC (data not shown). The effect of DXM is dose dependent and present at doses as low as $1 \mu M$ (Figure 5). No such effects were observed for methotrexate when tested in the same systems (Additional file 1).
GC effect can be reproduced ex vivo in synovial explants biopsies

SFMCs are in vitro surrogate replacements of the synovial biopsy complex milieu, although lacking important characteristics, such as the local complex intracellular interplay. To circumvent this caveat, we established explants from a synovial biopsy obtained from an RA patient at open surgery for hip replacement and tested the effect of GCs to confirm our results further. DXM treatment of the explants decreased the expression of $\mathrm{CP}$ and PAD4 but not PAD2, whereas parallel histologic investigation did not reveal major changes in the histologic composition of the samples. Once again, no such effects were observed for methotrexate (Additional file 2).

\section{Discussion}

Protein modification through posttranslational citrullination in the rheumatoid joint is thought to play an important role in perpetuation of local chronic inflammation in the presence of specific anticitrulline immunity. This is the first report showing that synovial citrullination is actively modulated by antirheumatic treatment.

Previous studies characterized synovial expression of citrullination, showing a general increase in the level of citrullination in the presence of active inflammation [2,4-6,11,15]. These early reports used one particular method for detection of citrullination, consisting of the chemical modification of the citrullinated tissue proteins to allow their recognition by an antibody raised against similarly modified citrullinated proteins [16]. However, this technique is no longer available, and in our hands, the only other antibody performing well in immunohistochemistry is F95 [10]. As with the modified anti-citrulline antibody, F95 is supposed to recognize a large array of citrullinated molecules independent of the amino acid context. We previously demonstrated that this antibody is able to recognize specifically at least one RA-relevant citrullinated antigen, citrullinated fibrinogen [17]. However, a somewhat more restricted pattern of citrullination, as compared with the modified anti-citrulline antibodies, has been observed both in synovial biopsies [11] and in other tissues, such as lungs of smoking healthy individuals [18]. By using this new antibody, De Rycke et al. [11] were able to describe an RA-specific intracellular F95 staining. We confirm this finding by the virtually absence of F95positive cells in synovial biopsies of healthy individuals.

Only few reports of PAD synovial expression are currently available $[2,11,19]$. The most thorough investigation of synovial PAD expression was performed by Foulquier et al. [2], showing correlation between expression of both PAD2 and PAD4 expression with the degree of synovial inflammation. We confirm these findings and identify the same correlation for the CP expression. 


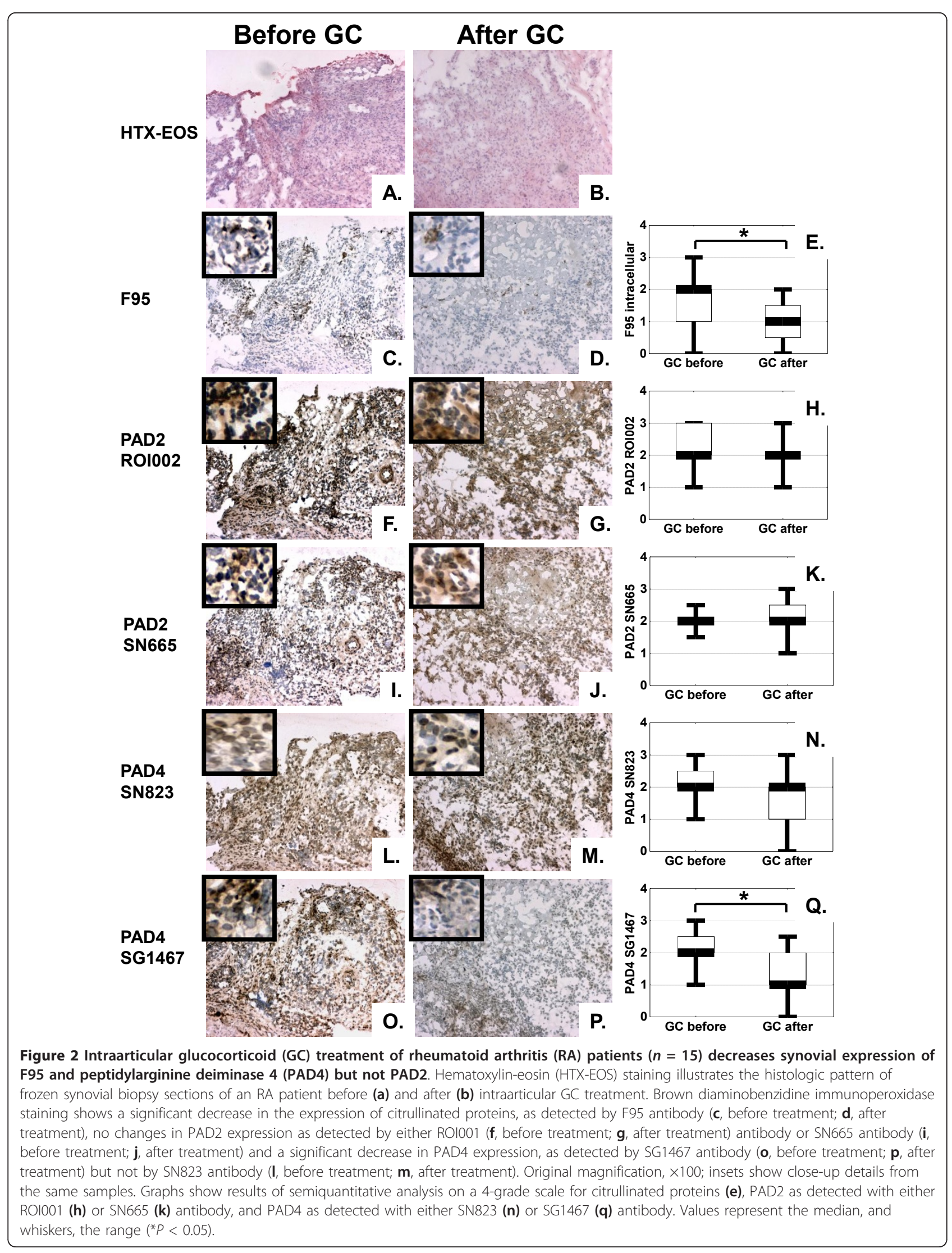




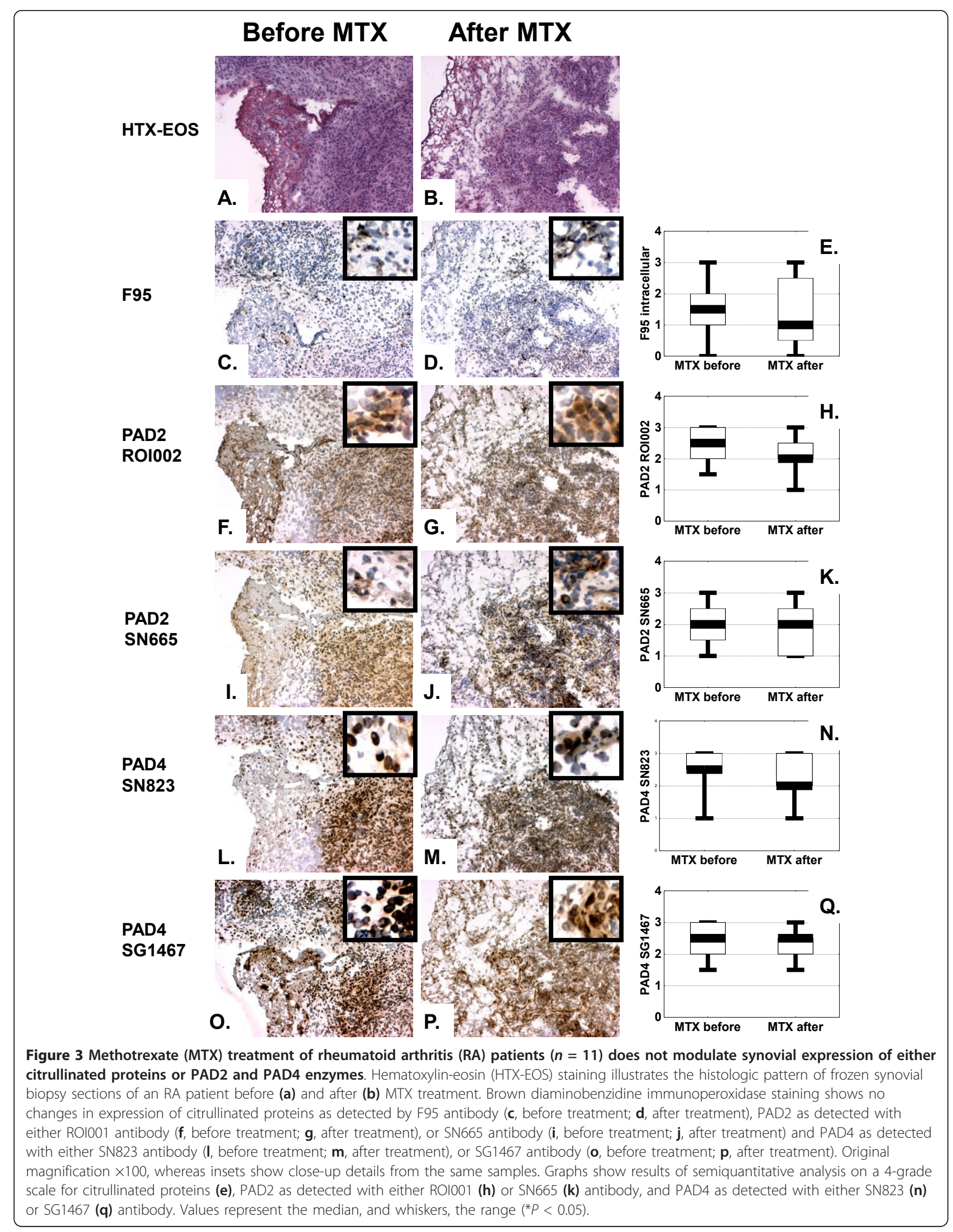




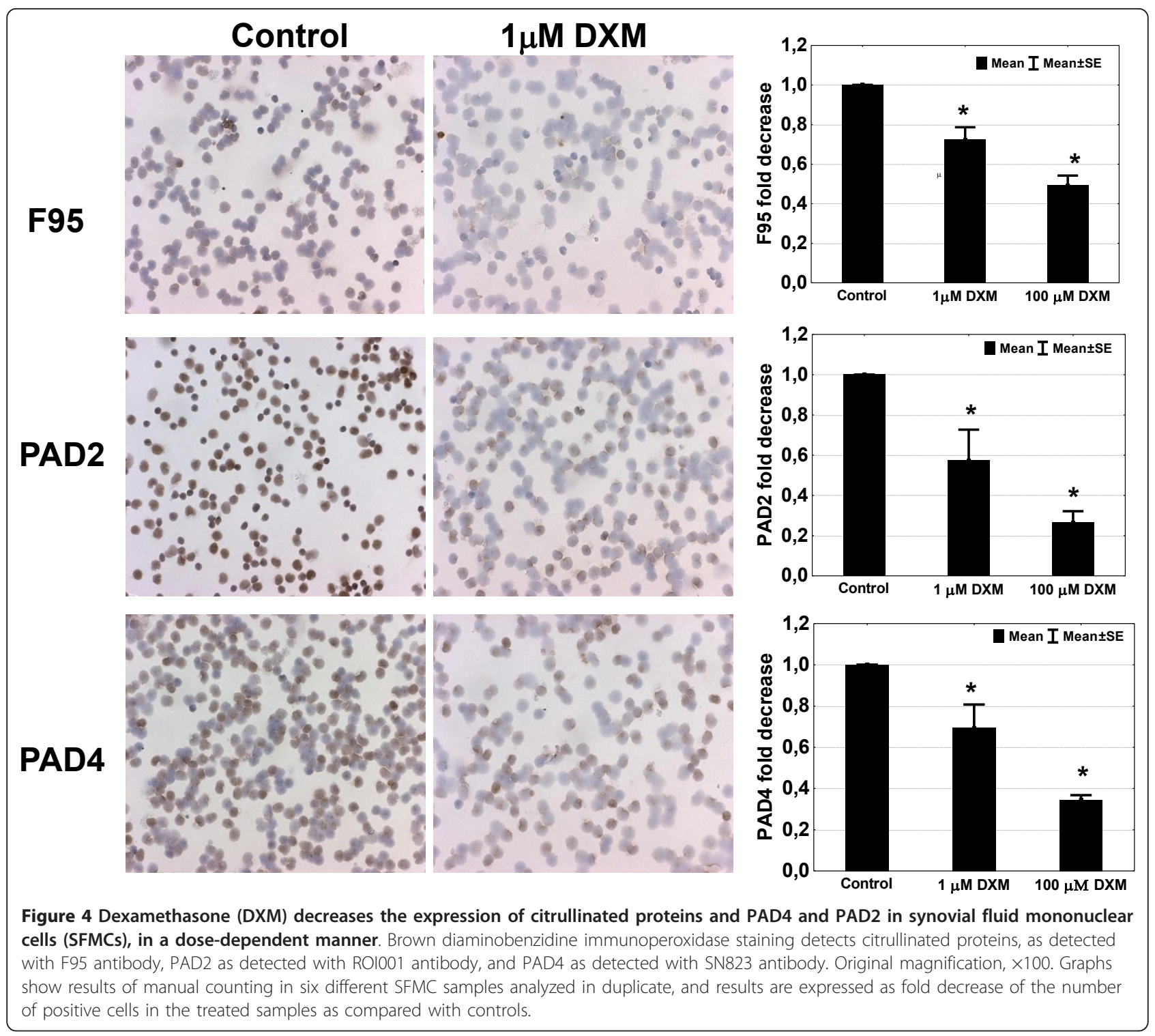

The novel finding of the current study is the reduction in citrullination and PAD expression induced by intraarticular GC, which was not observed after MTX treatment. One potential explanation for this difference is the different time points to obtain the follow-up biopsy, 2 weeks after treatment initiation with GCs, as compared with 8 weeks for MTX. However, the two different time points were chosen in accordance with the clinical expectation of maximal effect of the administered drug, which would theoretically increase the chance to observe a change, not only for GCs, but also for MTX. We were able also to demonstrate a direct effect of GCs independent of inflammation in our synovial explants. This is further supported by the results of the in vitro experiments, in which we observed a dosedependent effect of GCs despite obvious difficulties in standardization of a quantitative analysis by using immunohistochemistry on cells. Interestingly, although GCs decreased citrullination and PAD4 expression in SFMCs, no such effect was observed in PBMCs. This could be due to the lower baseline levels and, as a consequence, to the lower sensitivity to detect changes of expression of the investigated molecules in PBMCs as compared with SFMCs. Conversely, it could be due to different regulatory mechanisms and cellular activation states of PBMCs, as compared with SFMCs, as previously suggested [20]. Despite major advances in understanding the central role of citrullination and anticitrulline immunity in RA pathogenesis, we face a striking lack of knowledge regarding regulatory factors responsible for induction, perpetuation, and/or amelioration of the process of citrullination, both locally in 


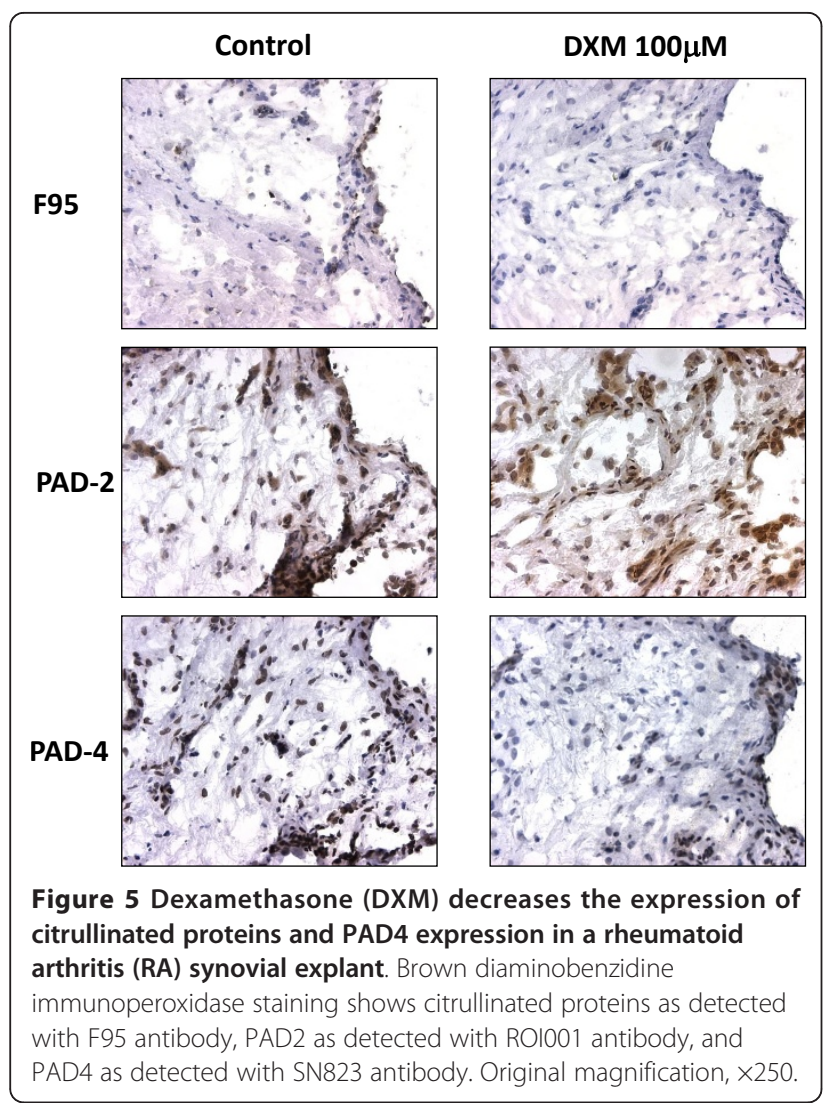

the joint and even more generally in other tissues where citrullination occurs either under physiologic (skin) [21] or pathologic conditions (lungs of smokers) [18,22]. It is generally accepted that citrullination accompanies inflammation, and it has been suggested that induction of citrullination by inflammatory stimuli such as TNF occurs after PAD4 activation and induction of signaling pathways dependent on NF- $\kappa$ B [23]. Interestingly, the antiinflammatory effects of GCs are at least partially dependent on NF- $\kappa \mathrm{B}$, as demonstrated by their lack of effect in animal models of acute inflammation in NF- $\kappa \mathrm{B}$ knockout mice [24]. In contrast, MTX appears to have limited effects on NF- $\kappa$ B activation, as demonstrated by high levels of activation in PBMCs of MTX-treated RA patients that can be reversed by anti-TNF agents [25]. These findings suggest that GCs might affect citrullination through PAD4 downregulation through an NF- $\kappa \mathrm{B}-$ dependent mechanism.

\section{Conclusion}

The inflamed RA synovium is characterized by high expression of intracellular CP and PAD4 enzyme that is reversed through GCs, but not MTX treatment. Further investigation of the exact mechanism of action and comparison with other antirheumatic drugs is warranted.

\section{Additional material}

Additional file 1: Methotrexate (MTX) has no effect on expression of citrullinated proteins and PAD4 and PAD2 in SFMCs. Brown diaminobenzidine immunoperoxidase staining detects citrullinated proteins, as detected with F95 antibody, PAD2 as detected with ROI001 antibody, and PAD4 as detected with SN823 antibody. Original magnification, $\times 200$. Graphs show results of manual counting in six different SFMC samples analyzed in duplicate, and results are expressed as fold decrease of the number of positive cells in the treated samples as compared with controls.

Additional file 2: MTX has no effect on expression of citrullinated proteins and PAD4 expression in an RA synovial explant. Brown diaminobenzidine immunoperoxidase staining shows citrullinated proteins as detected with F95 antibody, PAD2 as detected with RO1001 antibody, and PAD4 as detected with SN823 antibody. Original magnification, $\times 250$.

\section{Abbreviations}

ACPA: anti-citrullinated protein antibodies; CP: citrullinated protein; DMARD: disease-modifying antirheumatic drug; DXM: dexamethasone; FCS: fetal calf serum; GC: glucocorticoid; MC: mononuclear cell; MTX: methotrexate; PAD: peptidylarginine deiminase; PB: peripheral blood; RA: rheumatoid arthritis; SF: synovial fluid.

\section{Acknowledgements}

This work was supported in part by research funding from the European Community FP6 funding project AutoCure, FP7 funding project Gums and joints, Innovative Medicine Initiative Be the CURE, the Swedish Research Council, and through the regional agreement on medical training and clinical research (ALF) between Stockholm County Council and Karolinska Instituet.

\section{Author details}

${ }^{1}$ Department of Medicine, Rheumatology Unit, Karolinska University Hospital, Karolinska Institutet, SE- 141 86, Stockholm, Sweden. ²University of Alabama at Birmingham and Birmingham Veterans Administration Medical Center, S. $19^{\text {th }}$ Street, Birmingham, AL 35233, USA. ${ }^{3}$ Department of Biomolecular Chemistry, Radboud University Nijmegen, PO Box 9102, 6500 HC, Nijmegen, The Netherlands.

\section{Authors' contributions}

DM, AIC, and SR participated in study design, collection and interpretation of the data, and manuscript writing. ME and EaK participated in the collection of data. APN and GP participated in data collection, interpretation of the data, and manuscript writing. DM and SR contributed equally to this work. All authors read approved the final manuscript.

\section{Competing interests}

The authors declare that they have no competing interests.

Received: 28 July 2011 Revised: 11 October 2011

Accepted: 27 January 2012 Published: 27 January 2012

\section{References}

1. Klareskog L, Ronnelid J, Lundberg K, Padyukov L, Alfredsson L: Immunity to citrullinated proteins in rheumatoid arthritis. Annu Rev Immunol 2008, 26:651-75

2. Foulquier C, Sebbag M, Clavel C, Chapuy-Regaud S, Al Badine R, Méchin MC, Vincent C, Nachat R, Yamada M, Takahara H, Simon M, Guerrin M, Serre G: Peptidyl arginine deiminase type 2 (PAD-2) and PAD4 but not PAD-1, PAD-3, and PAD-6 are expressed in rheumatoid arthritis synovium in close association with tissue inflammation. Arthritis Rheum 2007, 56:3541-3553.

3. Schellekens GA, Visser H, de Jong BA, van den Hoogen FH, Hazes JM, Breedveld FC, van Venrooij WJ: The diagnostic properties of rheumatoid arthritis antibodies recognizing a cyclic citrullinated peptide. Arthritis Rheum 2000, 43:155-163. 
4. Vossenaar ER, Smeets TJ, Kraan MC, Raats JM, van Venrooij WJ, Tak PP: The presence of citrullinated proteins is not specific for rheumatoid synovial tissue. Arthritis Rheum 2004, 50:3485-3494.

5. Chapuy-Regaud S, Sebbag M, Baeten D, Clavel C, Foulquier C, De Keyser F, Serre G: Fibrin deimination in synovial tissue is not specific for rheumatoid arthritis but commonly occurs during synovitides. J Immunol 2005, 174:5057-5064.

6. Makrygiannakis $D$, af Klint $E$, Lundberg IE, Lofberg R, Ulfgren AK, Klareskog L, Catrina Al: Citrullination is an inflammation-dependent process. Ann Rheum Dis 2006, 65:1219-1222.

7. Lu MC, Lai NS, Yu HC, Huang HB, Hsieh SC, Yu CL: Anti-citrullinated protein antibodies bind surface-expressed citrullinated Grp78 on monocyte/macrophages and stimulate tumor necrosis factor alpha production. Arthritis Rheum 62:1213-1223.

8. Arnett FC, Edworthy SM, Bloch DA, Mcshane DJ, Fries JF, Cooper NS, Healey LA, Kaplan SR, Liang MH, Luthra HS, Medsger TS Jr, Mitchell DM, Neustadt DH, Pinals RS, Schaller JG, Sharp JT, Wilder RL, Hunder GJ: The American Rheumatism Association 1987 revised criteria for the classification of rheumatoid arthritis. Arthritis Rheum 1988, 31:315-324.

9. Nicholas AP, Whitaker JN: Preparation of a monoclonal antibody to citrullinated epitopes: its characterization and some applications to immunohistochemistry in human brain. Glia 2002, 37:328-336.

10. Nicholas AP, King JL, Sambandam T, Echols JD, Gupta KB, Mclnnis C Whitaker JN: Immunohistochemical localization of citrullinated proteins in adult rat brain. J Comp Neurol 2003, 459:251-266.

11. De Rycke L, Nicholas AP, Cantaert T, Kruithof E, Echols JD, Vandekerckhove B, Veys EM, De Keyser F, Baeten D: Synovial intracellular citrullinated proteins colocalizing with peptidyl arginine deiminase as pathophysiologically relevant antigenic determinants of rheumatoid arthritis-specific humoral autoimmunity. Arthritis Rheum 2005, 52:2323-2330

12. Vossenaar ER, Radstake TR, van der Heijden A, van Mansum MA, Dieteren C, de Rooij DJ, Barrera P, Zendman AJ, van Venrooij WJ: Expression and activity of citrullinating peptidylarginine deiminase enzymes in monocytes and macrophages. Ann Rheum Dis 2004, 63:373-381.

13. Raijmakers R, Vogelzangs J, Croxford JL, Wesseling P, van Venrooij WJ, Pruijn GJ: Citrullination of central nervous system proteins during the development of experimental autoimmune encephalomyelitis. J Comp Neurol 2005, 486:243-253.

14. Ishigami A, Ohsawa T, Asaga H, Akiyama K, Kuramoto M, Maruyama N: Human peptidylarginine deiminase type II: molecular cloning, gene organization, and expression in human skin. Arch Biochem Biophys 2002, 407:25-31.

15. Chang $X$, Yamada R, Suzuki A, Kochi $Y$, Sawada T, Yamamoto K: Citrullination of fibronectin in rheumatoid arthritis synovial tissue. Rheumatology (Oxford) 2005, 44:1374-1382.

16. Senshu $T$, Sato $T$, Inoue $T$, Akiyama $K$, Asaga $H$ : Detection of citrulline residues in deiminated proteins on polyvinylidene difluoride membrane. Anal Biochem 1992, 203:94-100.

17. Hermansson M, Artemenko K, Ossipova E, Eriksson H, Lengqvist J, Makrygiannakis D, Catrina Al, Nicholas AP, Klareskog L, Savitski M, Zubarev RA, Jakobsson PJ: MS analysis of rheumatoid arthritic synovial tissue identifies specific citrullination sites on fibrinogen. Proteomics Clin Appl 2010, 4:511-518.

18. Makrygiannakis D, Hermansson M, Ulfgren AK, Nicholas AP, Zendman AJ, Eklund A, Grunewald J, Skold CM, Klareskog L, Catrina Al: Smoking increases peptidylarginine deiminase 2 enzyme expression in human lungs and increases citrullination in BAL cells. Ann Rheum Dis 2008, 67:1488-1492.

19. Chang $X$, Yamada R, Suzuki A, Sawada T, Yoshino S, Tokuhiro S, Yamamoto K: Localization of peptidylarginine deiminase 4 (PADI4) and citrullinated protein in synovial tissue of rheumatoid arthritis. Rheumatology (Oxford) 2005, 44:40-50.

20. Catrina Al, Trollmo C, af Klint E, Engstrom M, Lampa J, Hermansson Y, Klareskog L, Ulfgren AK: Evidence that anti-tumor necrosis factor therapy with both etanercept and infliximab induces apoptosis in macrophages, but not lymphocytes, in rheumatoid arthritis joints: extended report. Arthritis Rheum 2005, 52:61-72.

21. Senshu T, Akiyama K, Nomura K: Identification of citrulline residues in the $\mathrm{V}$ subdomains of keratin $\mathrm{K} 1$ derived from the cornified layer of newborn mouse epidermis. Exp Dermatol 1999, 8:392-401.
22. Klareskog L, Stolt P, Lundberg K, Källberg H, Bengtsson C, Grunewald J, Rönnelid J, Harris HE, Ulfgren AK, Rantapää-Dahlqvist S, Eklund A,

Padyukov L, Alfredsson L: A new model for an etiology of rheumatoid arthritis: smoking may trigger HLA-DR (shared epitope)-restricted immune reactions to autoantigens modified by citrullination. Arthritis Rheum 2006, 54:38-46.

23. Neeli I, Khan SN, Radic M: Histone deimination as a response to inflammatory stimuli in neutrophils. J Immunol 2008, 180:1895-1902.

24. Cronstein BN, Montesinos MC, Weissmann G: Sites of action for future therapy: an adenosine-dependent mechanism by which aspirin retains its antiinflammatory activity in cyclooxygenase-2 and NFkappaB knockout mice. Osteoarthritis Cartilage 1999, 7:361-363.

25. Varani K, Massara A, Vincenzi F, Tosi A, Padovan M, Trotta F, Borea PA: Normalization of $A 2 A$ and $A 3$ adenosine receptor up-regulation in rheumatoid arthritis patients by treatment with anti-tumor necrosis factor alpha but not methotrexate. Arthritis Rheum 2009, 60:2880-2891.

\section{doi:10.1186/ar3702}

Cite this article as: Makrygiannakis et al: Local administration of glucocorticoids decreases synovial citrullination in rheumatoid arthritis. Arthritis Research \& Therapy 2012 14:R20

\section{Submit your next manuscript to BioMed Central and take full advantage of:}

- Convenient online submission

- Thorough peer review

- No space constraints or color figure charges

- Immediate publication on acceptance

- Inclusion in PubMed, CAS, Scopus and Google Scholar

- Research which is freely available for redistribution

Submit your manuscript at www.biomedcentral.com/submit
Ciomed Central 